\title{
Emotion Regulation and Trait Anxiety Are Predicted by the Microstructure of Fibers between Amygdala and Prefrontal Cortex
}

\author{
Annuschka Salima Eden, ${ }^{1}$ Jan Schreiber, ${ }^{4}$ 일ed Anwander, ${ }^{4}$ - Katharina Keuper, ${ }^{1,3}$ Inga Laeger, ${ }^{2}$ Peter Zwanzger, ${ }^{2}$ \\ Pienie Zwitserlood, ${ }^{5}$ - Harald Kugel, ${ }^{6}$ and Christian Dobel ${ }^{1,3}$ \\ ${ }^{1}$ Institute for Biomagnetism and Biosignalanalysis and ${ }^{2}$ Department of Psychiatry, University Hospital, 48149 Münster, Germany, ${ }^{3}$ Otto Creutzfeldt Center \\ for Cognitive and Behavioural Neuroscience, 48149 Münster, Germany, ${ }^{4}$ Max Planck Institute for Human Cognitive and Brain Sciences, 04103 Leipzig, \\ Germany, ${ }^{5}$ Westfälische Wilhelms-Universität, 48149 Münster, Germany, and ${ }^{6}$ Center of Radiology, Faculty of Medicine, 48149 Münster, Germany
}

Diffusion tensor imaging revealed that trait anxiety predicts the microstructural properties of a prespecified fiber tract between the amygdala and the perigenual anterior cingulate cortex. Besides this particular pathway, it is likely that other pathways are also affected. We investigated white matter differences in persons featuring an anxious or a nonanxious personality, taking into account all potential pathway connections between amygdala and anxiety-related regions of the prefrontal cortex (PFC). Diffusion-weighted images, measures of trait anxiety and of reappraisal use (an effective emotion-regulation style), were collected in 48 females. With probabilistic tractography, pathways between the amygdala and the dorsolateral PFC, dorsomedial PFC, ventromedial PFC, and orbitofrontal cortex (OFC) were delineated. The resulting network showed a direct ventral connection between amygdala and PFC and a second limbic connection following the fornix and the anterior limb of the internal capsule. Reappraisal use predicted the microstructure of pathways to all calculated PFC regions in the left hemisphere, indicating stronger pathways for persons with high reappraisal use. Trait anxiety predicted the microstructure in pathways to the ventromedial PFC and OFC, indexing weaker connections in trait-anxious persons. These effects appeared in the right hemisphere, supporting lateralization and top-down inhibition theories of emotion processing. Whereas a specific microstructure is associated with an anxious personality, a different structure subserves emotion regulation. Both are part of a broad fiber tract network between amygdala and PFC.

Key words: amygdala; DTI; PFC; reappraisal use; top-down inhibition; trait anxiety

\section{Introduction}

The interplay between amygdala and prefrontal cortex (PFC) is central to the regulation of emotions. Crucial components of this interplay are top-down inhibition processes manifesting themselves in downregulation of the amygdala by medial PFC ( $\mathrm{mPFC}$; Bishop, 2007). A greater functional connectivity between the amygdala and the MPFC was reported in persons with low anxiety (Pezawas et al., 2005). Investigating fiber connections in white matter, Kim and Whalen (2009) applied diffusion tensor imaging (DTI) and found that trait anxiety, a stable tendency to respond with anxiety, predicted the microstructure of a ventral amygdalaPFC pathway. Persons high in trait anxiety showed lower values of fractional anisotropy (FA; Basser and Pierpaoli, 1996) on this

\footnotetext{
Received July 26, 2014; revised Jan. 31, 2015; accepted Feb. 3, 2015.

Author contributions: A.S.E., K.K., I.L., Pe.Z., Pi.Z., and C.D. designed research;A.S.E. and H.K. performed research; J.S., A.A., H.K., and C.D. contributed unpublished reagents/analytic tools; A.S.E., J.S., and A.A. analyzed data; A.S.E., J.S., A.A., K.K., I.L., Pe.Z., Pi.Z., H.K., and C.D. wrote the paper.

This work was supported by the Interdisciplinary Center for Clinical Research (Grant D03/021/10).

The authors declare no competing financial interests.

Correspondence should be addressed to Annuschka Salima Eden, Institute for Biomagnetism and Biosignalanalysis, Malmedyweg 15, 48143 Münster, Germany. E-mail: Annuschka.Eden@uni-muenster.de.

DOI:10.1523/JNEUROSCI.3659-14.2015

Copyright $\odot 2015$ the authors $\quad 0270-6474 / 15 / 356020-08 \$ 15.00 / 0$
}

tract to the perigenual anterior cingulate cortex, i.e., weaker connections. It is likely that a larger network of amygdala-PFC connections is affected in trait anxiety (for review, see Ray and Zald, 2012). Data by Kim and Whalen (2009) support the idea that anxiety is associated with ineffective top-down inhibition. These dysfunctional processes might be attributable to an attenuated use of reappraisal, a coping strategy involving reinterpretation of the emotional meaning of stimuli. Low reappraisal results in low activity in PFC regions and in high amygdala activity (Ochsner et al., 2002, 2004; Kim and Hamann, 2007). In women, the microstructural foundation for this interplay is related to the integrity of white matter pathways between amygdala and PFC (Zuurbier et al., 2013).

Anatomical knowledge about amygdala-PFC connections mostly derives from primates. Because of close cytoarchitectural homology between primates and humans (Petrides and Mackey, 2006; Jbabdi et al., 2013), a transfer of findings seems reasonable but awaits further support. The MPFC and the orbitofrontal cortex (OFC) receive direct input from the amygdala (for an overview, see Barbas and Zikopoulos, 2006), whereas the lateral PFC receives less, and mostly indirect, input via the cingulate or posterior OFC (Ray and Zald, 2012). Studies investigating amygdala-PFC connections in relation to anxiety have mostly focused on 
Table 1. Means and SDs of demographic, behavioral, and fractional anisotropy (in target regions) data, separately for both anxiety groups

\begin{tabular}{|c|c|c|c|c|c|c|c|c|c|}
\hline \multirow[b]{2}{*}{ Trait anxiety group } & \multirow[b]{2}{*}{ Trait anxiety score } & \multirow[b]{2}{*}{ Reappraisal score } & \multirow[b]{2}{*}{ Age } & \multirow[b]{2}{*}{ Years of schooling } & \multirow[b]{2}{*}{ IQ } & \multicolumn{4}{|l|}{$\mathrm{FA}$} \\
\hline & & & & & & $\mathrm{OFC}$ & vmPFC & $\mathrm{dmPFC}$ & dIPFC \\
\hline Low & $27.08 \pm 2.43$ & $27.75 \pm 6.03$ & $25.38 \pm 3.67$ & $13 \pm 0$ & $115.17 \pm 13.06$ & $\begin{array}{l}\mathrm{L}: 0.533 \pm 0.017 \\
\mathrm{R}: 0.541 \pm 0.017\end{array}$ & $\begin{array}{l}\mathrm{L}: 0.544 \pm 0.015 \\
\mathrm{R}: 0.541 \pm 0.014\end{array}$ & $\begin{array}{l}\mathrm{L}: 0.553 \pm 0.015 \\
\mathrm{R}: 0.554 \pm 0.012\end{array}$ & $\begin{array}{l}\mathrm{L}: 0.545 \pm 0.019 \\
\mathrm{R}: 0.541 \pm 0.012\end{array}$ \\
\hline High & $57.58 \pm 4.65$ & $23.04 \pm 6.52$ & $26.92 \pm 5.99$ & $13 \pm 0$ & $107.00 \pm 25.11$ & $\begin{array}{l}\mathrm{L}: 0.522 \pm 0.030 \\
\mathrm{R}: 0.527 \pm 0.017\end{array}$ & $\begin{array}{l}\mathrm{L}: 0.488 \pm 0.152 \\
\mathrm{R}: 0.531 \pm 0.013\end{array}$ & $\begin{array}{l}\mathrm{L}: 0.505 \pm 0.157 \\
\mathrm{R}: 0.519 \pm 0.112\end{array}$ & $\begin{array}{l}\mathrm{L}: 0.471 \pm 0.183 \\
\mathrm{R}: 0.508 \pm 0.111\end{array}$ \\
\hline
\end{tabular}

L, Left hemisphere; $R$, right hemisphere.

specific and direct connections, such as to the insula or via the uncinate fasciculus. They neglected indirect routes via long association fibers (Modi et al., 2013; Baur et al., 2013a,b).

Our aim was to investigate white matter alterations in persons with high and low trait anxiety, along multiple pathways connecting amygdala and PFC. We collected diffusion-weighted magnetic resonance images and applied probabilistic tractography (Behrens et al., 2007) to reconstruct all potential pathways between the amygdala and PFC regions associated with anxietyrelated processes. A rather large body of literature established an association of anxiety with right-hemispheric activity (Davidson et al., 1990), and thus we hypothesized trait anxiety to be associated with weaker right-hemispheric connections. Mechanisms of reappraisal are less investigated, but there is some evidence for left-hemispheric lateralization of reappraisal (Ochsner et al., 2002) as well as higher metabolic activity in left frontal regions in reappraisal users (Kim et al., 2012). Consequently, reappraisal was expected to be associated with stronger left-hemispheric connections brought forth by intensive use.

\section{Materials and Methods}

Subjects

Three hundred ten nonclinical volunteers completed an on-line version of the Spielberger Trait Anxiety Inventory (Spielberger et al., 1983). On the basis of individual trait scores, right-handed (according to the Edinburgh Handedness Inventory; Oldfield, 1971) female participants were selected if they scored $\leq 30$ or $\geq 50$. In a next step, they were matched for age. This established two groups of participants $(n=24$ each), one with low anxiety [LA; mean trait score, 27.08 (SD, 2.43); mean age, 25.38 (SD, 3.679)] and one with high anxiety [HA; mean trait score, 27.08 (SD, 2.43); mean age, 25.38 (SD, 3.67)], that did not differ for age ( $\mathrm{df}=46$, $T=1.414, p=0.166$ ) nor years of schooling. All group members were medically healthy and had no history of psychiatric medication or mental disorders, as verified by the Mini International Neuropsychiatric Interview (version 5.0.0) of the Diagnostic Statistical Manual-IV (Ackenheil et al., 1999). The participants that were excluded from the two groups did not fulfill one or more of the required inclusion criteria. All procedures were cleared by the ethical review board of the Ärztekammer WestfalenLippe, and subjects gave informed consent for their participation.

\section{Procedure}

To control for intelligence differences between groups, the Wechsler Adult Intelligence Scale (German version of the WAIS-III; Von Aster et al., 2006) was administered individually to every subject $2 \mathrm{~d}$ before image acquisition. No significant differences were found between the HA and LA groups (HA: mean, 107.00; SD, 25.11; LA: mean, 115.17; SD, 13.06; $T=1.414, p=0.164)$. Participants completed the German version of the Emotion Regulation Questionnaire (Gross and John, 2003), which measures reappraisal use. The two groups displayed significant differences in reappraisal use (HA: mean, 23.04; SD, 6.52; LA: mean, 27.75; SD, 6.03; $T=2.598, p=0.013$; see Table 1 for means separated by group).

\section{Image acquisition}

Participants were instructed to lie still and stay awake throughout the entire scanning procedure. Diffusion MRI (dMRI) and structural T1weighted images were acquired on a 3T MR scanner (Intera 3.0T; Philips Medical Systems), with an inner bore diameter of $60 \mathrm{~cm}$, equipped with
Quasar-Dual Gradients with two modes, either $40 \mathrm{mT} / \mathrm{m}$ gradient strength and $200 \mathrm{mT} / \mathrm{m} / \mathrm{ms}$ slew rate for general imaging or $80 \mathrm{mT} / \mathrm{m}$ gradient strength and $100 \mathrm{mT} / \mathrm{m} / \mathrm{ms}$ slew rate for diffusion imaging.

Diffusion MRI. High-angular resolution dMRI data were acquired using a six-channel head coil with a single-shot spin echo EPI sequence (TE, $55 \mathrm{~ms}$; TR, 15,623 ms; image matrix, $128 \times 128$; FOV, $240 \times 240 \mathrm{~mm}^{2}$ ), providing 60 diffusion-encoding gradient directions with a $b$ value of $1000 \mathrm{~s} / \mathrm{mm}^{2}$ and a single measurement without a diffusion-weighting gradient $\left(b=0 \mathrm{~s} / \mathrm{mm}^{2}\right)$. Seventy-eight axial slices with $1.88 \mathrm{~mm}$ thickness were acquired in an interleaved manner, covering the whole brain. This resulted in cubic voxels of $1.88 \mathrm{~mm}$ edge length. Parallel image acquisition was applied using SENSE with an acceleration factor of 2 and a scan duration of $20 \mathrm{~min}$.

Anatomical MRI. The T1-weighted images were acquired with a 3D nonequilibrium gradient echo sequence (turbo field echo) with waterselective excitation. Contrast preparation of magnetization consisted of a nonselective inversion pulse every $1020 \mathrm{~ms}$. Imaging parameters were as follows: TR, $9.3 \mathrm{~ms}$; final TE, $4.4 \mathrm{~ms}$; pulse angle, $9^{\circ}$; FOV, $300 \times 239 \times$ $234 \mathrm{~mm}^{3}$ (foot-head $\times$ anterior-posterior $\times$ right-left); cubic voxels of 1.17 mm edge length; SENSE acceleration factor 2' scan duration, $8.43 \mathrm{~min}$.

\section{dMRI preprocessing}

Before data processing, dMRI volumes that were corrupted by movement of the participants were removed from the datasets. First, an automatic method was used to remove volumes of low quality. The algorithm is based on the fact that motion eliminates the signal in a slice when motion occurs during its acquisition. Usually, the average voxel intensity of two consecutive slices does not change much. Only when motion extinguishes the signal in parts of a slice does its average voxel intensity differ greatly from its neighbors' and indicate corruption of the volume. In a following control step, visual inspection of the datasets ensured the satisfactory quality of the remaining data. The cleaned dMRIs were interpolated to $1 \mathrm{~mm}$ isotropic resolution, aligned with the MNI template, and corrected for motion and eddy-current effects in one step with a single interpolation. The diffusion tensor and the FA maps were computed by use of the FSL software package (http://fsl.fmrib.ox.ac. uk/fsl/fsl-4.1.9; Smith et al., 2004; Woolrich et al., 2009; Jenkinson et al., 2012).

\section{Regions for connectivity analysis}

Based on the literature, four regions in the PFC were defined: the ventromedial PFC (vmPFC; Buckholtz et al., 2008), the dorsomedial PFC (dmPFC; Kim et al., 2011), the dorsolateral PFC (dlPFC; Stein et al., 2007), and the OFC (Zald and Kim, 1996a,b; Rauch et al., 1997; Sladky et al., 2012). Since the precise anatomical locations and boundaries of these areas have not yet been defined beyond controversy (Roy et al., 2012), there was no suitable ready-to-use atlas that comprised all four PFC areas for our purposes. Thus, we manually created an atlas that included the dmPFC, dlPFC, OFC, and vmPFC based on the atlas introduced by Oishi (type II WMPM; Oishi et al., 2009). The ventral and dorsal regions were separated by an axial cutting plane at $z=5(\mathrm{MNI})$. The posterior end of the ROIs was defined at $y=0(\mathrm{MNI})$. This atlas was morphed on the individual brains using nonlinear registration (Avants et al., 2008) obtained from a registration of the FA template (FMRIB58_FA_1 mm supplied with FSL) onto the individual FA map. Figure 1 illustrates the defined PFC areas applied in this study. The amygdala regions were obtained by registration of the combined population maps of the amygdala parcellation (Solano-Castiella et al., 2010) to each individual 
FA map, and they were thresholded at a value of 3. The average volumes of the left and right amygdala were 1478 and $1586 \mathrm{~mm}^{3}$, respectively.

Analysis of white matter microstructure Probabilistic tractography based on the balland-stick model (Behrens et al., 2007) that is implemented in the FSL software package was used to create the connectivity maps between amygdala and the PFC regions. These connectivity maps indicate for every voxel by how many probabilistic tracks it has been crossed. One thousand tracks were started in every voxel of the amygdala, but only those that reached one of the prefrontal regions were considered. Starting a fixed number of tracks in every voxel of the amygdala masks leads to a different number of probabilistic tracks in every subject, because of different sizes of indi-

vidual amygdalae. To compensate for this effect, all voxel values in the connectivity maps were normalized by dividing them by the volume of the individual amygdala. Tracks were only seeded in the amygdala and not in the PFC regions, as pilot testing revealed that only a very small fraction of the tracks seeded in the PFC areas reached the amygdala so that the statistical power of this testing was not sufficient.

To evaluate differences in white matter coherence along the connecting pathways, values of FA were compared between the groups. This was achieved by a region-based analysis method (Snook et al., 2007; Faria et al., 2010) that considered only voxels on the center line of the white matter within the pathways defined by the connectivity maps. The central line was defined by computing the skeleton of each individual's FA map as implemented in the tract-based spatial statistics software package (TBSS, http://fsl.fmrib.ox.ac.uk/fsl/fslwiki/TBSS; Smith et al., 2006), taking into account only voxels with an FA value higher than 0.4 (Fig. $1 B$, green). To define the target-specific ROI, the connectivity maps were thresholded at a specific level for every target region. These levels were computed separately by averaging the $90 \%$ quantiles of all individual normalized connectivity maps. The FA values on the skeleton within this mask were averaged.

\section{Amygdala-prefrontal pathways}

The individual connectivity maps for each prefrontal connection were normalized with the transformation obtained from the atlas registration, averaged across participants, and thresholded at the target-specific level. The anatomical locations of the fiber pathways were evaluated based on the anatomical slices and a 3D volume rendering using the LIPSIA software (Lohmann et al., 2001).

\section{Statistical analysis}

To test the influence of trait anxiety and reappraisal use on the pathway strength between amygdala (seed) and PFC regions (targets), multiple hierarchical regressions were calculated individually for both hemispheres, with the factors trait anxiety (high trait anxiety vs low trait anxiety, dummy coded), the individual reappraisal use score, and the individual IQ score. The factor IQ was added to check the specificity of the resultant pathways for emotion-related characteristics. There is evidence for a positive correlation between FA and IQ (Schmithorst et al., 2005). If the delineated microstructure is emotion specific, IQ should not explain additional variance.

The FA values on the calculated pathways between seed and targets (dmPFC, dlPFC, vmPFC, and OFC, respectively) served as dependent variables. Note that because of a priori knowledge of asymmetric hemispheric processing, we calculated hierarchical regressions and set up different hierarchies for both hemispheres. In the left hemisphere, the factor reappraisal use was expected to explain most of the variance and thus was the first variable to enter the regression, followed by the factor trait anxiety and IQ as a third factor. To underline the hypothesis-driven approach, we also tested the model where trait anxiety was the first factor. Based on the literature, we expected no effects. In the right hemisphere, we expected the factor trait anxiety to explain most of the variance. Hence, trait anxiety was the first to enter this regression, followed by reappraisal use and, finally, IQ. As above, we also tested the alternative model with reappraisal use as the first factor.

\section{Results}

After an anatomical description of the fiber pathway connections between seed and target regions, the results of the statistical analyses of the FA values of these pathways will be reported.

Figure 2 shows the calculated pathways between the amygdala and the four target regions of the prefrontal cortex: the OFC, the vmPFC, the dmPFC, and the dlPFC, (see Table 1 for FA means separated by group). The calculated pathways of both hemispheres did not show qualitative differences, so that the connections are exemplarily shown in the right hemisphere. The ventral PFC regions (Fig. $2 A, B$ ) are connected with the amygdala via a direct ventral pathway following the uncinated fascicle. Additionally, a strong indirect limbic connection was found. This pathway followed the fornix and the temporopulvinar tract to the posterior thalamic nuclei, continuing through the anterior thalamic radiation to the frontal lobe. The latter connection was also observed for the dorsal PFC regions (Fig. 2C,D). The dorsal regions and the vmPFC also showed a connection with the amygdala via the cingulum.

\section{Multiple hierarchical regressions}

There are correlations between use of reappraisal and trait anxiety $(r=-0.377 ; p=0.008)$, but both of these variables did not correlate with IQ (reappraisal: $r=-0.130, p=0.379$; trait anxiety: $r=-0.182, p=0.216$; all Pearson correlations). The intercorrelations between trait anxiety and "reappraisal use" stress the use of methods that take this intercorrelation into account, such as regression analysis.

The results of the multiple hierarchical regression analyses with factor trait anxiety group as the first predictor (right hemisphere) will be reported first, followed by the results of the multiple hierarchical regression analyses with the factor reappraisal use as the first predictor (left hemisphere).

The factor trait anxiety group (high trait anxiety vs low trait anxiety) significantly predicted the FA values on the white matter microstructure between the amygdala and the vmPFC $(r=0.350$, $\mathrm{df}=47, F=6.441, T=-2.538, p=0.015)$ and between the amygdala and the OFC $(r=0.395, \mathrm{df}=47, F=8.520, T=$ $-2.919, p=0.005$ ), both in the right hemisphere (see Table 2 for a list of all statistical parameters for all multiple hierarchical re- 
A
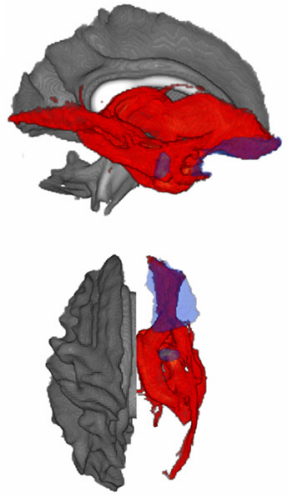

B
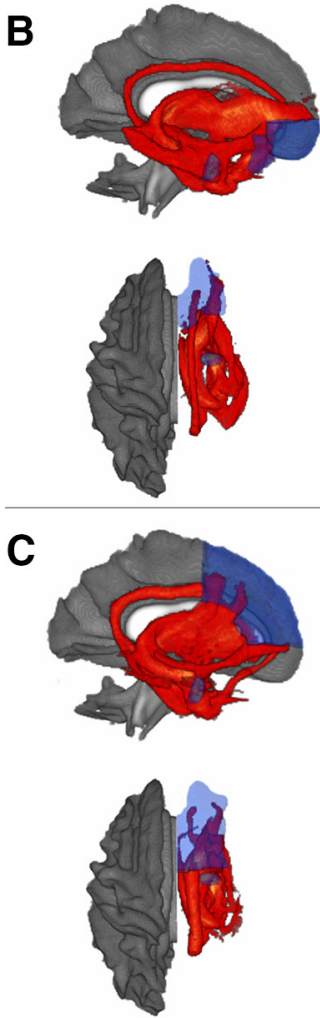

D
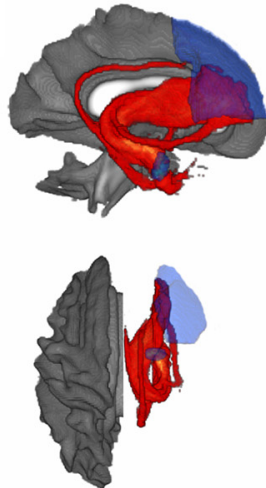

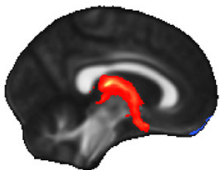

$x=5$

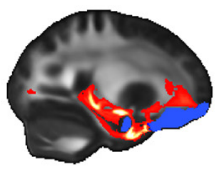

$x=25$

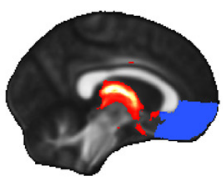

$x=5$

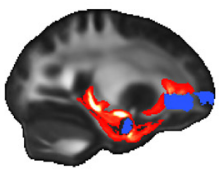

$x=25$

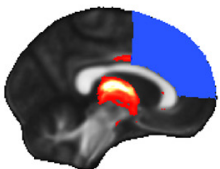

$x=5$

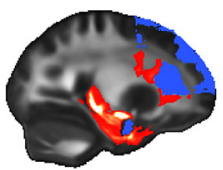

$x=25$

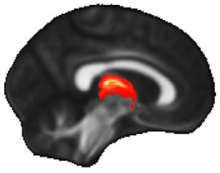

$x=5$

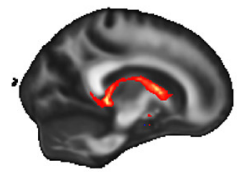

$x=15$

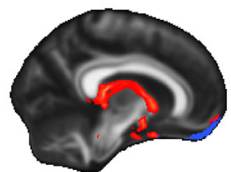

$x=10$
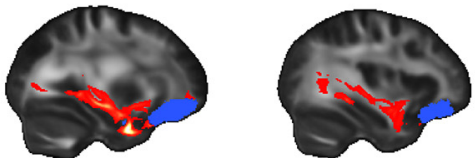

$x=30$

$x=35$

$=40$

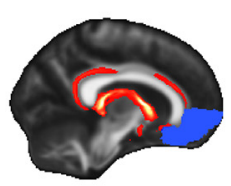

$x=10$
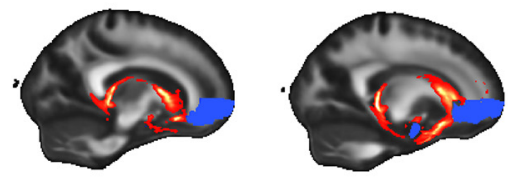

$x=15$

$x=20$
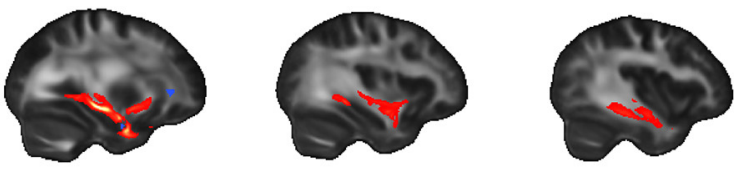

$x=30$

$x=35$

$x=40$
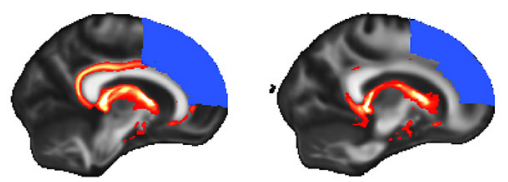

$x=15$

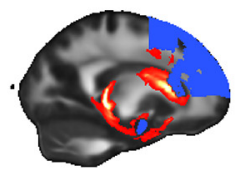

$x=20$

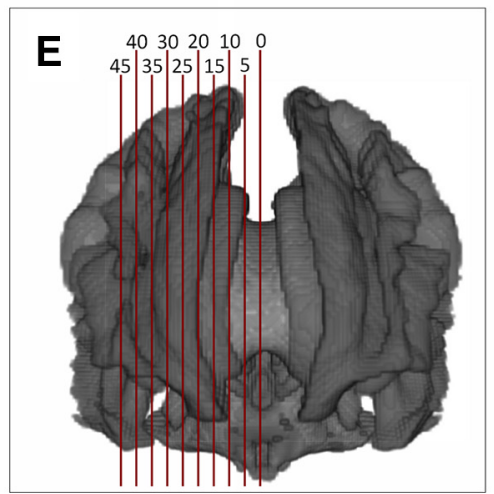

$x=10$

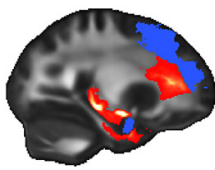

$x=25$

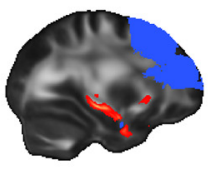

$x=30$

Figure 2. $\quad \boldsymbol{A}-\boldsymbol{D}$, Left, Three-dimensional sagittal and superior views of tracts between amygdala and PFC regions: $\boldsymbol{A}$, orbitofrontal cortex; $\boldsymbol{B}$, ventromedial PFC; $\boldsymbol{C}$, dorsomedial PFC; $\boldsymbol{D}$, dorsolateral PFC. Renderings show the normalized number of tracts through each voxel (red). Seed and target regions are displayed in blue. For normalization, each voxel was divided by the amygdala's size. $\boldsymbol{E}$, Slices illustrating the tracts' localization from medial to lateral. The distance between slices is $5 \mathrm{~mm}$.

gressions). The FA values on the right-hemispheric white matter microstructure between the amygdala and the dmPFC $(r=0.215$, $\mathrm{df}=47, F=2.240, T=-1,497, p=0.141)$ or the dlPFC $(r=$ $0.209, \mathrm{df}=47, F=2.097, T=-1,448, p=0.154)$ could not significantly be predicted. In line with our hypotheses, the factor reappraisal did not explain additional variance in this hemisphere (vmPFC: $r=0.377$, df $=47, F=3.731, T=1.009, p=0.318$; OFC: $r=0.397, \mathrm{df}=47, F=4.209, T=-0.266, p=0.792$; 


\begin{tabular}{|c|c|c|c|c|c|c|c|}
\hline ROI & Model & $R^{2}$ & Cor. $R^{2}$ & $F$ & TA $\beta$ & $\mathrm{R} \beta$ & IQ $\beta$ \\
\hline \multirow[t]{4}{*}{ Right dmPFC } & TA & 0.05 & 0.03 & 2.24 & -0.22 & & \\
\hline & $T A, R$ & 0.06 & 0.02 & 1.41 & -0.17 & 0.12 & \\
\hline & $T A, R, I Q$ & 0.06 & -0.00 & 0.95 & -0.18 & 0.12 & -0.05 \\
\hline & $\mathrm{R}$ & 0.03 & 0.01 & 1.56 & & 0.18 & \\
\hline \multirow[t]{4}{*}{ Right dIPFC } & TA & 0.04 & 0.02 & 2.10 & -0.21 & & \\
\hline & $T A, R$ & 0.06 & 0.02 & 1.53 & -0.16 & 0.15 & \\
\hline & $T A, R, I Q$ & 0.06 & 0.00 & 1.01 & -0.16 & 0.15 & -0.02 \\
\hline & R & 0.04 & 0.02 & 2.06 & & 0.21 & \\
\hline \multirow[t]{4}{*}{ Right vmPFC } & $\mathrm{TA}$ & 0.12 & 0.10 & $6.44^{*}$ & $-0.35^{*}$ & & \\
\hline & $T A, R$ & 0.14 & 0.10 & $3.73^{*}$ & -0.30 & 0.15 & \\
\hline & $T A, R, I Q$ & 0.18 & 0.13 & $3.31^{*}$ & $-0.34^{*}$ & 0.16 & -0.21 \\
\hline & R & 0.07 & 0.05 & 3.21 & & 0.26 & \\
\hline \multirow[t]{4}{*}{ Right OFC } & TA & 0.16 & 0.14 & $8.52^{* *}$ & $-0.40^{* *}$ & & \\
\hline & $T A, R$ & 0.16 & 0.12 & $4.21^{*}$ & $-0.41^{* *}$ & -0.04 & \\
\hline & $T A, R, I Q$ & 0.17 & 0.11 & $2.92^{*}$ & $-0.39^{*}$ & -0.04 & 0.10 \\
\hline & R & 0.01 & -0.01 & 0.54 & & 0.11 & \\
\hline \multirow[t]{4}{*}{ Left dmPFC } & R & 0.09 & 0.07 & $4.74^{*}$ & & $0.31^{*}$ & \\
\hline & $\mathrm{R}, \mathrm{TA}$ & 0.11 & 0.07 & 2.69 & -0.12 & 0.26 & \\
\hline & $\mathrm{R}, \mathrm{TA}, \mathrm{IQ}$ & 0.11 & 0.05 & 1.87 & -0.14 & 0.27 & -0.08 \\
\hline & TA & 0.05 & 0.03 & 2.27 & -0.22 & & \\
\hline \multirow[t]{4}{*}{ Left dIPFC } & R & 0.11 & 0.09 & $5.85^{*}$ & & $0.34^{*}$ & \\
\hline & $\mathrm{R}, \mathrm{TA}$ & 0.14 & 0.10 & $3.73^{*}$ & -0.18 & 0.27 & \\
\hline & $\mathrm{R}, \mathrm{TA}, \mathrm{IQ}$ & 0.15 & 0.09 & 2.52 & -0.20 & 0.28 & -0.07 \\
\hline & TA & 0.08 & 0.06 & 3.91 & -0.28 & & \\
\hline \multirow[t]{4}{*}{ Left vmPFC } & $\mathrm{R}$ & 0.11 & 0.09 & $5.65^{*}$ & & $0.33^{*}$ & \\
\hline & $\mathrm{R}, \mathrm{TA}$ & 0.13 & 0.09 & $3.36^{*}$ & -0.15 & 0.28 & \\
\hline & $\mathrm{R}, \mathrm{TA}, \mathrm{IQ}$ & 0.14 & 0.08 & 2.29 & -0.17 & 0.28 & -0.07 \\
\hline & TA & 0.06 & 0.04 & 3.13 & -0.25 & & \\
\hline \multirow[t]{4}{*}{ Left OFC } & $\mathrm{R}$ & 0.09 & 0.07 & $4.59^{*}$ & & $0.30^{*}$ & \\
\hline & $\mathrm{R}, \mathrm{TA}$ & 0.11 & 0.07 & 2.68 & -0.13 & 0.25 & \\
\hline & $\mathrm{R}, \mathrm{TA}, \mathrm{IQ}$ & 0.15 & 0.09 & 2.51 & -0.17 & 0.27 & -0.20 \\
\hline & TA & 0.05 & 0.03 & 2.44 & -0.22 & & \\
\hline
\end{tabular}

Model parameters for each predictor variable for hierarchical regression analyses are shown. Dependent variables are fractional anisotropy values of pathway microstructure between amygdala and prefrontal cortex regions. ROI, Region of interest; TA, trait anxiety; $\mathrm{R}$, reappraisal use. ${ }^{*} p<0.05{ }^{* *} p<0.01$.

dmPFC: $r=0.242, \mathrm{df}=47, F=1.405, T=0.769, p=0.446$; dlPFC: $r=0.252, \mathrm{df}=47, F=1.530, T=0.982, p=0.331)$ and IQ (vmPFC: $r=0.429$, df $=47, F=3.308, T=-1.502, p=$ 0.140 ; OFC: $r=0.408, \mathrm{df}=47, F=2.923, T=0.674, p=0.504$; dmPFC: $r=0.247, \mathrm{df}=47, F=0.953, T=-0.322, p=0.749$; dlPFC: $r=0.253, \mathrm{df}=47, F=1.005, T=-0.148, p=0.883)$. As expected, the alternative model with reappraisal as first factor did not become significant in any of the four (right-hemispheric) analyses.

The factor reappraisal significantly predicted the FA values on the calculated white matter microstructure between the amygdala and all four predefined PFC regions in the left hemisphere (dmPFC: $r=0.306, \mathrm{df}=47, F=4.741, T=2.177, p=$ 0.035; dlPFC: $r=0.336$, df $=47, F=5.854, T=2.419, p=0.020$; vmPFC: $r=0.331, \mathrm{df}=47, F=5.652, T=2.377, p=0.022$; OFC: $r=0.301, \mathrm{df}=47, F=4.591, T=2.143, p=0.037)$. The addition of the factor anxiety group did not significantly increase the explanation of variance in any of the regions (dmPFC: $r=$ 0.327, $\mathrm{df}=47, F=2.686, T=-0.816, p=0.419$; dlPFC: $r=$ 0.377 , df $=47, F=3.727, T=-1.238, p=0.222$; vmPFC: $r=0.361, \mathrm{df}=47, F=3.364, T=-1.033 p=0.307$; OFC: $r=$ $0.326, \mathrm{df}=47, F=2.678, T=-0.887, p=0.380$ ) or IQ (dmPFC: $r=0.336, \mathrm{df}=47, F=1.870, T=-0.564, p=0.576$; dlPFC: $r=$ $0.383, \mathrm{df}=47, F=2.521, T=-0.485, p=0.630$; vmPFC: $r=$ $0.367, \mathrm{df}=47, F=2.285, T=-0.491, p=0.626$; OFC: $r=0.382$, $\mathrm{df}=47, F=2.512, T=-1.433, p=0.159)$. As hypothesized, the alternative model with trait anxiety entering as first factor did not reveal any effects.

\section{Discussion}

We investigated the microstructural properties of pathway connections between the amygdala and $\mathrm{PFC}$ regions deemed relevant for anxiety and emotion regulation. The results provide direct evidence for stronger connectivity between amygdala and vmPFC and OFC of the right hemisphere in persons with low trait anxiety. Emotion regulation was expressed as stronger connectivity between amygdala and vmPFC, OFC, dmPFC, and dlPFC of the left hemisphere in persons with high reappraisal use.

We collected diffusion-weighted images (dMRI) and applied probabilistic tractography to compute all tracks between amygdala and PFC regions individually for both hemispheres. The resulting white matter circuitry included (parts of) the uncinate fasciculus, cingulum, fornix, anterior thalamic radiation, and inferior fronto-occipital fasciculus. Strong connectivity via the uncinate fasciculus was observed for the pathways to vmPFC and OFC, which was neither seen in the pathway network to dlPFC nor to dmPFC. These connections, especially to vmPFC, fit with findings from dMRI studies on humans and animals (Croxson et al., 2005; Carlson et al., 2013; Jbabdi et al., 2013) and with anatomical studies that reported extensive anatomical connections between the amygdala and the PFC. For instance, in rats and monkeys, it was shown that the amygdala is connected to prefrontal cortex by direct amygdalo-cortical projections (Nauta, 1961; Krettek and Price, 1974, 1977a), and indirectly via the thalamus (Nauta, 1962; Krettek and Price, 1974, 1977a,b). In rhesus monkeys, the ventromedial region of PFC receives both direct and indirect tracts stemming from the amygdala, but the dorsolateral PFC does not get such input (Porrino et al., 1981). These findings suggested that the ventromedial region may be regarded as the "limbic portion of the frontal association cortex." The longer, presumably indirect routes found in our study have not been focused on and rarely have been addressed in human dMRI studies on emotion processing or anxiety. Reviewing the role of the PFC in emotion-cognition interactions, Ray and Zald (2012) emphasized that studies on nonhuman primates reveal large variability concerning direct projections between the amygdalae and regions of the PFC and that direct projections between amygdala and dIPFC are "extremely weak". It may thus be surprising that we find such strong connections between amygdala and prefrontal regions. However, there is ample evidence for indirect pathways, most notably through the thalamus, in both animals and humans.

Recent research using tractography in humans provided further evidence for strong connections between hippocampus/ amygdala and thalamus. The amygdala connects with the anterior thalamus via the fornix and uncinate fasciculus and with the pulvinar via the temporopulvinar tract (Zarei et al., 2010). Similarly, Linke et al. (2012) reported indirect pathways from the amygdala to the OFC, namely via the anterior and posterior thalami. Note that these studies did not specifically target the connection between the amygdala and prefrontal regions.

With multiple hierarchical regressions, we analyzed the relationship of these determined fiber connections with trait anxiety and reappraisal use by means of hypothesis-driven, hemispherespecific models. Given accumulating evidence for an asymmetric involvement of the PFC, with a right-hemispheric dominance for anxiety and anxiety-related processes (Stewart et al., 1988; Hermann et al., 1992; Hellige, 1993; O’Carroll et al., 1993; Petruzzello 
and Landers, 1994; Lucey et al., 1995; Stapleton et al., 1997; Bremner et al., 1999; Nitschke et al., 1999; Wiedemann et al., 1999; Davidson et al., 2000; Davidson, 2002; Pizzagalli et al., 2002; Smit et al., 2007, Harmon-Jones et al., 2010), we expected our structural trait anxiety effects to be particularly visible in the right hemisphere. Based on evidence for a left-hemispheric lateralization of reappraisal use (Ochsner et al., 2002; Jackson et al., 2003; Kim and Bell, 2006) and recently observed left-sided biases of metabolic activity in the superior frontal gyrus in frequent reappraisers (Kim et al., 2012), we expected reappraisal use effects to be most prominent in the left hemisphere. We set up the hierarchies of the multiple regression analysis accordingly, with trait anxiety as the first factor in the analyses of the right hemisphere and with reappraisal use as the first factor for the left hemisphere.

The following methodological details are important to consider. First, we chose a hypothesis-based approach, analyzing the microstructure of only those tracts to PFC regions that have consistently been associated with emotion-related processes. Different from prior studies, all tracks, including longer pathways between the two structures, were considered. We calculated the tracts for subsequent FA analysis on our sample, not relying on data from thematically different experimental contexts. This is more conservative than a whole-brain approach, where significant regions are selected, analyzed, and interpreted post hoc. Second, we also adopted the hypothesis-based approach in the statistical analysis. As mentioned above, anxiety and use of reappraisal is related to hemisphere-specific networks. Whereas anxiety is primarily (but not exclusively) related to processes of right-hemispheric amygdala and PFC (Reiman et al., 1984; Heller et al., 1995), emotion regulation is primarily associated with left-hemispheric processing in these structures (Wheeler et al., 1993; Jackson et al., 2003; Kim and Bell, 2006; Kim et al., 2012). This differential hemispheric involvement in different aspects of emotion processing and regulation supports the hypotheses by Davidson and colleagues (Davidson et al., 1987, 1990, 2000; Davidson and Tomarken, 1989; Davidson, 1992, 1995, 2002; Sutton and Davidson, 1997). In low traitanxious persons, there was no higher FA in pathways to the dorsomedial and the dorsolateral part of the PFC. One reason might be that the amygdalar inhibition by these PFC regions operates via general mechanisms, such as changes in the neurotransmitter system. Such mechanisms might not be reflected in FA values of connecting pathways (Ray and Zald, 2012). An alternative explanation is that our atlas comprised comparably wide boundaries around the $\mathrm{dmPFC}$ and the dlPFC. Although this was deliberately done as not to miss potentially important fibers, it could have led to an attenuation of the expected effect.

Some caveats and open questions should be addressed in future studies. First, we probabilistically tracked fiber pathways from amygdala to PFC within each hemisphere, focusing on noncrossing fibers. However, animal studies have shown that a small percentage of connecting fibers between the amygdala and the PFC crosses the corpus callosum (Mascagni et al., 1993; McDonald and Mascagni, 1996). A second caveat concerns the origin of the calculated fibers within the amygdala. We mapped the amygdala in each participant and treated the entire amygdala as seed region. Yet, the amygdala is a heterogeneous structure, with various substructures and nuclei (Sah et al., 2003), each with different functions and connections with different areas in the brain. It is thus a challenge for future DTI studies to differentiate connections between amygdala substructures and regions of the PFC. Third, because women are especially prone to develop anxiety disorders (see Somers et al., 2006) and to avoid additional variance attributable to existing brain-activation differences be- tween men and women (Gong et al., 2011), we included only female persons. Studies revealed the sexually dimorphic nature of the cortex, limbic structures, and connecting fibers and how such sex differences might impact the development of affective disorders (for review, see Cahill, 2006). Zuurbier et al. (2013) observed correlations between reappraisal and FA values in the left frontal part of uncinate fasciculus in women, but not in men. Thus, it is likely that at least some of the connections between amygdala and PFC reported here cannot easily be transferred to men.

Although our results have to be interpreted within the constraints of the above-mentioned limitations, we believe that our data make an important contribution to the understanding of the neuroanatomical basis of anxiety and emotion regulation. Our findings provide strong support for theories of and (fMRI) studies on top-down inhibition, by offering a structural network that might underlie the so far mostly theoretically, behaviorally, and functionally argued/established network.

Our data show that different structural networks are responsible for trait anxiety and reappraisal use. Neural models on the generation and regulation of emotions stress the importance of the interplay between automatic and voluntary processes (e.g., use of reappraisal; Ochsner and Gross, 2007; Phillips et al., 2008) and emphasize the role of the amygdala and PFC regions (particularly OFC) for this interplay. The attempt to study voluntary and automatic processes in separation may seem futile (Phillips et al., 2008), especially in therapeutic settings. Nevertheless, we identified a hemispherically specialized functional architecture involved in the mediation of anxiety and reappraisal use, with stronger connectivity between amygdala, OFC, and vmPFC in each hemisphere. Given the correlational nature of these data, we cannot make claims about the development of the relationship. It is a challenge for future research to investigate how manipulating one of these processes [e.g., using the anxiolytic effects of noninvasive brain stimulation (Zwanzger et al., 2009)] impacts on the other, especially on the microstructure involved. Such investigations might help to develop new strategies for the treatment of anxiety disorders and to identify persons at risk.

\section{References}

Ackenheil M, Stotz G, Dietz-Bauer R, Vossen A (1999) Deutsche Fassung des Mini-International Neuropsychiatric Interview. München: Psychiatrische Universitätsklinik München.

Avants BB, Epstein CL, Grossman M, Gee JC (2008) Symmetric diffeomorphic image registration with cross-correlation: evaluating automated labeling of elderly and neurodegenerative brain. Med Image Anal 12:26-41. CrossRef Medline

Barbas H, Zikopoulos B (2006) Sequential and parallel circuits for emotional processing in primate orbitofrontal cortex. In: The orbitofrontal cortex (Zald DH, Rauch SL, eds), pp 57-91. Oxford: Oxford UP.

Basser PJ, Pierpaoli C (1996) Microstructural and physiological features of tissues elucidated by quantitative-diffusion-tensor MRI. J Magn Reson 111:209-219.

Baur V, Hänggi J, Langer N, Jäncke L (2013a) Resting-state functional and structural connectivity within an insula-amygdala route specifically index state and trait anxiety. Biol Psychiatry 73:85-92. CrossRef Medline

Baur V, Brühl AB, Herwig U, Eberle T, Rufer M, Delsignore A, Jäncke L, Hänggi J (2013b) Evidence of frontotemporal structural hypoconnectivity in social anxiety disorder: a quantitative fiber tractography study. Hum Brain Mapp 34:437-446. CrossRef Medline

Behrens TE, Berg HJ, Jbabdi S, Rushworth MF, Woolrich MW (2007) Probabilistic diffusion tractography with multiple fibre orientations: what can we gain? Neuroimage 34:144-155. CrossRef Medline

Bishop SJ (2007) Neurocognitive mechanisms of anxiety: an integrative account. Trends Cogn Sci 11:307-316. CrossRef Medline

Bremner JD, Staib LH, Kaloupek D, Southwick SM, Soufer R, Charney DS (1999) Neural correlates of exposure to traumatic pictures and sound in combat veterans with and without posttraumatic stress disorder: a posi- 
tron emission tomography study. Biol Psychiatry 45:806-816. CrossRef Medline

Buckholtz JW, Callicott JH, Kolachana B, Hariri AR, Goldberg TE, Genderson M, Egan MF, Mattay VS, Weinberger DR, Meyer-Lindenberg A (2008) Genetic variation in MAOA modulates ventromedial prefrontal circuitry mediating individual differences in human personality. Mol Psychiatry 13:313-324. CrossRef Medline

Cahill L (2006) Why sex matters for neuroscience. Nat Rev Neurosci 7:477484. CrossRef Medline

Carlson JM, Cha J, Harmon-Jones E, Mujica-Parodi LR, Hajcak G (2013) Influence of the BDNF genotype on amygdalo-prefrontal white matter microstructure is linked to nonconscious attention bias to threat. Cereb Cortex 24:2249-2257. CrossRef Medline

Croxson PL, Johansen-Berg H, Behrens TE, Robson MD, Pinsk MA, Gross CG, Richter W, Richter MC, Kastner S, Rushworth MF (2005) Quantitative investigation of connections of the prefrontal cortex in the human and macaque using probabilistic diffusion tractography. J Neurosci 25 : 8854-8866. CrossRef Medline

Davidson RJ (1992) Anterior cerebral asymmetry and the nature of emotion. Brain Cogn 20:125-151. CrossRef Medline

Davidson RJ (1995) Cerebral asymmetry, emotion and affective style. In: Brain asymmetry (Davidson RJ, Hugdahl K, eds), pp 361-387. Cambridge, MA: MIT.

Davidson RJ (2002) Anxiety and affective style: role of prefrontal cortex and amygdala. Biol Psychiatry 51:68-80. CrossRef Medline

Davidson RJ, Tomarken AJ (1989) Laterality and emotion: an electrophysiological approach. Handb Neuropsychol 3:419-441.

Davidson RJ, Mednick D, Moss E, Saron C, Schaffer CE (1987) Ratings of emotion in faces are influenced by the visual field to which stimuli are presented. Brain Cogn 6:403-411. CrossRef Medline

Davidson RJ, Ekman P, Saron CD, Senulis JA, Friesen WV (1990) Approach-withdrawal and cerebral asymmetry: emotional expression and brain physiology: I. J Pers Soc Psychol 58:330-341. CrossRef Medline

Davidson RJ, Jackson DC, Kalin NH (2000) Emotion, plasticity, context, and regulation: perspectives from affective neuroscience. Psychol Bull 126:890-909. CrossRef Medline

Faria AV, Zhang J, Oishi K, Li X, Jiang H, Akhter K, Hermoye L, Lee SK, Hoon A, Stashinko E, Miller MI, van Zijl PC, Mori S (2010) Atlas-based analysis of neurodevelopment from infancy to adulthood using diffusion tensor imaging and applications for automated abnormality detection. Neuroimage 52:415-428. CrossRef Medline

Gong G, He Y, Evans AC (2011) Brain connectivity gender makes a difference. Neuroscientist 17:575-591. CrossRef Medline

Gross JJ, John OP (2003) Individual differences in two emotion regulation processes: implications for affect, relationships, and well-being. J Pers Soc Psychol 85:348-362. CrossRef Medline

Harmon-Jones E, Gable PA, Peterson CK (2010) The role of asymmetric frontal cortical activity in emotion-related phenomena: a review and update. Biol Psychol 84:451-462. CrossRef Medline

Heller W, Etienne MA, Miller GA (1995) Patterns of perceptual asymmetry in depression and anxiety: implications for neuropsychological models of emotion and psychopathology. J Abnorm Psychol 104:327-333. CrossRef Medline

Hellige JB (1993) Hemispheric asymmetry: what's right and what's left. Cambridge, MA: Harvard UP.

Hermann BP, Wyler AR, Blumer D, Richey ET (1992) Ictal fear: lateralizing significance and implications for understanding the neurobiology of pathological fear states. Neuropsychiatry Neuropsychol Behav Neurol 5:205-210.

Jackson DC, Mueller CJ, Dolski I, Dalton KM, Nitschke JB, Urry HL, Rosenkranz MA, Ryff CD, Singer BH, Davidson RJ (2003) Now you feel it, now you don't: frontal brain electrical asymmetry and individual differences in emotion regulation. Psychol Sci 14:612-617. CrossRef Medline

Jbabdi S, Lehman JF, Haber SN, Behrens TE (2013) Human and monkey ventral prefrontal fibers use the same organizational principles to reach their targets: tracing versus tractography. J Neurosci 33:3190-3201. CrossRef Medline

Jenkinson M, Beckmann CF, Behrens TE, Woolrich MW, Smith SM (2012) FSL. Neuroimage 62:782-790. CrossRef Medline

Kim KJ, Bell MA (2006) Frontal EEG asymmetry and regulation during childhood. Ann N Y Acad Sci 1094:308-312. CrossRef Medline

Kim MJ, Whalen PJ (2009) The structural integrity of an amygdala-pre- frontal pathway predicts trait anxiety. J Neurosci 29:11614-11618. CrossRef Medline

Kim MJ, Gee DG, Loucks RA, Davis FC, Whalen PJ (2010) Anxiety dissociates dorsal and ventral medial prefrontal cortex functional connectivity with the amygdala at rest. Cereb Cortex 21:1667-1673. CrossRef Medline

Kim SH, Hamann S (2007) Neural correlates of positive and negative emotion regulation. J Cogn Neurosci 19:776-798. CrossRef Medline

Kim SH, Cornwell B, Kim SE (2012) Individual differences in emotion regulation and hemispheric metabolic asymmetry. Biol Psychol 89:382-386. CrossRef Medline

Krettek JE, Price JL (1974) A direct input from the amygdala to the thalamus and the cerebral cortex. Brain Res 67:169-174. CrossRef Medline

Krettek JE, Price JL (1977a) The cortical projections of the mediodorsal nucleus and adjacent thalamic nuclei in the rat. J Comp Neurol: 171:157191. CrossRef Medline

Krettek JE, Price JL (1977b) Projections from the amygdaloid complex to the cerebral cortex and thalamus in the rat and cat. J Comp Neurol 172: 687-722. CrossRef Medline

Linke J, Witt SH, King AV, Nieratschker V, Poupon C, Gass A, Hennerici MG, Rietschel M, Wessa M (2012) Genome-wide supported risk variant for bipolar disorder alters anatomical connectivity in the human brain. Neuroimage, 59:3288-3296. CrossRef Medline

Lohmann G, Mueller K, Bosch V, Mentzel H, Hessler S, Chen L, Zysset S, von Cramon DY (2001) Lipsia-a new software system for the evaluation of functional magnetic resonance images of the human brain. Comput Med Imaging Graph 25:449-457. CrossRef Medline

Lucey JV, Costa DC, Blanes T, Busatto GF, Pilowsky LS, Takei N, Marks IM, Ell PJ, Kerwin RW (1995) Regional cerebral blood flow in obsessivecompulsive disordered patients at rest. Differential correlates with obsessive-compulsive and anxious-avoidant dimensions. Br J Psychiatry 167:629-634. CrossRef Medline

Mascagni F, McDonald AJ, Coleman JR (1993) Corticoamygdaloid and corticocortical projections of the rat temporal cortex: a Phaseolus vulgaris leucoagglutinin study. Neuroscience 57:697-715. CrossRef Medline

McDonald AJ, Mascagni F (1996) Cortico-cortical and cortico-amygdaloid projections of the rat occipital cortex: a Phaseolus vulgaris leucoagglutinin study. Neuroscience 71:37-54. CrossRef Medline

Modi S, Trivedi R, Singh K, Kumar P, Rathore RK, Tripathi RP, Khushu S (2013) Individual differences in trait anxiety are associated with white matter tract integrity in fornix and uncinate fasciculus: preliminary evidence from a DTI based tractography study. Behav Brain Res 238:188192. CrossRef Medline

Nauta WJ (1961) Fibre degeneration following lesions of the amygdaloid complex in the monkey. J Anat 95:515-531. Medline

Nauta WJ (1962) Neural associations of the amygdaloid complex in the monkey. Brain 85:505-520. CrossRef Medline

Nitschke JB, Heller W, Palmieri PA, Miller GA (1999) Contrasting patterns of brain activity in anxious apprehension and anxious arousal. Psychophysiology 36:628-637. CrossRef Medline

O'Carroll RE, Moffoot AP, Van Beck M, Dougall N, Murray C, Ebmeier KP, Goodwin GM (1993) The effect of anxiety induction on the regional uptake of $99 \mathrm{mTc}$-Exametazime in simple phobia as shown by single photon emission tomography (SPET). J Affect Disord 28:203-210. CrossRef Medline

Ochsner KN, Gross JJ (2007) The neural architecture of emotion regulation. Handbook Emot Regul 1:87-109.

Ochsner KN, Bunge SA, Gross JJ, Gabrieli JDE (2002) Rethinking feelings: an FMRI study of the cognitive regulation of emotion. J Neurosci 14: 1215-1229. CrossRef Medline

Ochsner KN, Ray RD, Cooper JC, Robertson ER, Chopra S, Gabrieli JD, Gross JJ (2004) For better or for worse: neural systems supporting the cognitive down- and up-regulation of negative emotion. Neuroimage 23:483499. CrossRef Medline

Oishi K, Faria A, Jiang H, Li X, Akhter K, Zhang J, Hsu JT, Miller MI, van Zijl PC, Albert M, Lyketsos CG, Woods R, Toga AW, Pike GB, Rosa-Neto P, Evans A, Mazziotta J, Mori S (2009) Atlas-based whole brain white matter analysis using large deformation diffeomorphic metric mapping: application to normal elderly and Alzheimer's disease participants. Neuroimage 46:486-499. CrossRef Medline

Oldfield RC (1971) The assessment and analysis of handedness: The Edinburgh inventory. Neuropsychologia 9:97-113. CrossRef Medline

Petrides M, Mackey S (2006) The orbitofrontal cortex: sulcal and gyral mor- 
phology and architecture. In: The orbitofrontal cortex (Zald DH, Rauch SL, eds), pp 19-37. Oxford: Oxford UP.

Petruzzello SJ, Landers DM (1994) State anxiety reduction and exercise: does hemispheric activation reflect such changes? Med Sci Sports Exer 26:1028-1035. Medline

Pezawas L, Meyer-Lindenberg A, Drabant EM, Verchinski BA, Munoz KE, Kolachana BS, Egan MF, Mattay VS, Hariri AR, Weinberger DR (2005) 5-HTTLPR polymorphism impacts human cingulate-amygdala interactions: a genetic susceptibility mechanism for depression. Nat Neurosci 8:828-834. CrossRef Medline

Phillips ML, Ladouceur CD, Drevets WC (2008) A neural model of voluntary and automatic emotion regulation: implications for understanding the pathophysiology and neurodevelopment of bipolar disorder. Mol Psychiatry 13:833-857. CrossRef Medline

Pizzagalli DA, Nitschke JB, Oakes TR, Hendrick AM, Horras KA, Larson CL, Abercrombie HC, Schaefer SM, Koger JV, Benca RM, Pascual-Marqui RD, Davidson RJ (2002) Brain electrical tomography in depression: the importance of symptom severity, anxiety and melancholic features. Biol Psychiatry 52:73-85. CrossRef Medline

Porrino LJ, Crane AM, Goldman-Rakic PS (1981) Direct and indirect pathways from the amygdala to the frontal lobe in rhesus monkeys. J Comp Neurol 198:121-136. CrossRef Medline

Rauch SL, Savage CR, Alpert NM, Fischman AJ, Jenike MA (1997) The functional neuroanatomy of anxiety: a study of three disorders using positron emission tomography and symptom provocation. Biol Psychiatry 42:446-452. CrossRef Medline

Ray RD, Zald DH (2012) Anatomical insights into the interaction of emotion and cognition in the prefrontal cortex. Neurosci Biobehav Rev 36: 479-501. CrossRef Medline

Reiman EM, Raichle ME, Butler FK, Herscovitch P, Robins E (1984) A focal brain abnormality in panic disorder, a severe form of anxiety. Nature 310:683-685. CrossRef Medline

Roy M, Shohamy D, Wager TD (2012) Ventromedial prefrontal-subcortical systems and the generation of affective meaning. Trends Cogn Sci 16:147156. CrossRef Medline

Sah P, Faber ES, Lopez De Armentia M, Power J (2003) The amygdaloid complex: anatomy and physiology. Physiol Rev 83:803-834. CrossRef Medline

Schmithorst VJ, Wilke M, Dardzinski BJ, Holland SK (2005) Cognitive functions correlate with white matter architecture in a normal pediatric population: a diffusion tensor MRI study. Hum Brain Mapp 26:139-147. CrossRef Medline

Sladky R, Höflich A, Atanelov J, Kraus C, Baldinger P, Moser E, Lanzenberger R, Windischberger C (2012) Increased neural habituation in the amygdala and orbitofrontal cortex in social anxiety disorder revealed by fMRI. PLoS One 7:e50050. CrossRef Medline

Smit DJ, Posthuma D, Boomsma DI, De Geus EJ (2007) The relation between frontal EEG asymmetry and the risk for anxiety and depression. Biol Psychol 74:26-33. CrossRef Medline

Smith SM, Jenkinson M, Woolrich MW, Beckmann CF, Behrens TE, Johansen-Berg H, Bannister PR, Luca M de, Drobnjak I, Flitney DE, Niazy RK, Saunders J, Vickers J, Zhang Y, Stefano N de, Brady JM, Matthews PM (2004) Advances in functional and structural MR image analysis and implementation as FSL. Neuroimage 23 [Suppl 1]:S208-S219.

Smith SM, Jenkinson M, Johansen-Berg H, Rueckert D, Nichols TE, Mackay CE, Watkins KE, Ciccarelli O, Cader MZ, Matthews PM, Behrens TE (2006) Tract-based spatial statistics: voxelwise analysis of multi-subject diffusion data. Neuroimage 31:1487-1505. CrossRef Medline
Snook L, Plewes C, Beaulieu C (2007) Voxel based versus region of interest analysis in diffusion tensor imaging of neurodevelopment. Neuroimage 34:243-252. CrossRef Medline

Solano-Castiella E, Anwander A, Lohmann G, Weiss M, Docherty C, Geyer S, Reimer E, Friederici AD, Turner R (2010) Diffusion tensor imaging segments the human amygdala in vivo. Neuroimage, 49:2958-2965. CrossRef Medline

Somers JM, Goldner EM, Waraich P, Hsu L (2006) Prevalence and incidence studies of anxiety disorders: a systematic review of the literature. Can J Psychiatry 51:100-113. Medline

Spielberger CD, Jacobs G, Russell S, Crane RS (1983) Assessment of anger: the State-Trait Anger Scale. In: Advances in personality assessment, Vol 2 (Butcher JN, Spielberger CD, eds), pp 161-185. Mahwah, NJ: Lawrence Erlbaum Associates.

Stapleton JM, Morgan MJ, Liu X, Yung BC, Phillips RL, Wong DF, Shaya EK, Dannals RF, London ED (1997) Cerebral glucose utilization is reduced in second test session. J Cereb Blood Flow Metab 17:704-712. Medline

Stein MB, Simmons AN, Feinstein JS, Paulus MP (2007) Increased amygdala and insula activation during emotion processing in anxietyprone subjects. Am J Psychiatry 164:318-327. CrossRef Medline

Stewart RS, Devous MD Sr, Rush AJ, Lane L, Bonte FJ (1988) Cerebral blood flow changes during sodium-lactate-induced panic attacks. Am J Psychiatry 145:442-449. CrossRef Medline

Sutton SK, Davidson RJ (1997) Prefrontal brain asymmetry: a biological substrate of the behavioral approach and inhibition systems. Psychol Sci 8:204-210. CrossRef

Von Aster M, Neubauer A, Horn R (2006) Wechsler Intelligenztest für Erwachsene (WIE). Deutschsprachige Bearbeitung und Adaptation des WAIS-III von David Wechsler. Frankfurt/Main, Germany: Harcourt Test Services.

Wheeler RE, Davidson RJ, Tomarken AJ (1993) Frontal brain asymmetry and emotional reactivity: a biological substrate of affective style. Psychophysiology 30:82-89. Medline

Wiedemann G, Pauli P, Dengler W, Lutzenberger W, Birbaumer N, Buchkremer G (1999) Frontal brain asymmetry as a biological substrate of emotions in patients with panic disorders. Arch Gen Psychiatry 56:78-84. CrossRef Medline

Woolrich MW, Jbabdi S, Patenaude B, Chappell M, Makni S, Behrens T, Beckmann C, Jenkinson M, Smith SM (2009) Bayesian analysis of neuroimaging data in FSL. Neuroimage 45:S173-S186. CrossRef Medline

Zald DH, Kim SW (1996a) Anatomy and function of the orbital frontal cortex: I. Anatomy, neurocircuitry, and obsessive-compulsive disorder. J Neuropsychiatry Clin Neurosci 8:125-138. CrossRef Medline

Zald DH, Kim SW (1996b) Anatomy and function of the orbital frontal cortex, II: Function and relevance to obsessive-compulsive disorder. J Neuropsychiatry Clin Neurosci 8:249-261. CrossRef Medline

Zarei M, Patenaude B, Damoiseaux J, Morgese C, Smith S, Matthews PM, Barkhof F, Rombouts SA, Sanz-Arigita E, Jenkinson M (2010) Combining shape and connectivity analysis: an MRI study of thalamic degeneration in Alzheimer's disease. Neuroimage 49:1-8. CrossRef Medline

Zuurbier LA, Nikolova YS, Åhs F, Hariri AR (2013) Uncinate fasciculus fractional anisotropy correlates with typical use of reappraisal in women but not men. Emotion 13:385-390. CrossRef Medline

Zwanzger P, Fallgatter AJ, Zavorotnyy M, Padberg F (2009) Anxiolytic effects of transcranial magnetic stimulation-an alternative treatment option in anxiety disorders? J Neural Transm 116:767-775. CrossRef Medline 